Research Article

\title{
Physical Training Information System of College Sports Based on Big Data Mobile Terminal
}

\author{
Xianfeng Dong (iD \\ The Fundamental Department, Yinchuan University of Energy, Yinchuan 750105, Ningxia, China \\ Correspondence should be addressed to Xianfeng Dong; dxf801125@163.com
}

Received 12 June 2021; Revised 15 July 2021; Accepted 17 August 2021; Published 29 August 2021

Academic Editor: Sang-Bing Tsai

Copyright (C) 2021 Xianfeng Dong. This is an open access article distributed under the Creative Commons Attribution License, which permits unrestricted use, distribution, and reproduction in any medium, provided the original work is properly cited.

\begin{abstract}
The development of information technology is changing all walks of life. People's health problem is more and more prominent; people begin to talk about the reform of college sports training. Sports no longer rely on individual games, but on the comprehensive strength of science and technology competition. The fierce competition for Olympic gold medal in modern competitive sports is largely due to the competition of scientific and technological strength of various countries. China has also conducted a lot of research on sports information and made some achievements. Through the investigation, we know that, at present, the provincial level sports teams have established the relevant sports training information management system, which is very effective. The latest scientific and technological achievements are combined with sports to establish the university sports information system. The purpose of this paper is to analyze the university sports physical training information system based on big data mobile terminal, study the big data embedded system, improve the effect of sports skills training, and meet the social demand for high skilled sports talents. This paper uses the literature method, experimental investigation method, and big data spectral clustering algorithm-related experiments to study the advantages of big data and uses the value of big data and embedded system model to study the university sports physical fitness training information system based on big data mobile terminal. The results show that $40.6 \%$ of college students spend more time in physical exercise, based on the application of big data embedded system in college sports training; it is of great significance to arrange sports training methods to improve students' sports training performance.
\end{abstract}

\section{Introduction}

As the core part of a PE teacher's professional skills, physical training in colleges and universities is not only the prerequisite for $\mathrm{PE}$ teachers to teach, but also the key factor of a PE teacher's professional skills. According to the survey, the current physical training level of physical education graduates in colleges and universities is not satisfactory. A considerable number of students think that their physical training level in colleges and universities is difficult to meet the needs of educational practice. Under the background of basic education reform and career development, the benefit analysis of physical exercise in sports colleges is not enough to improve the effect of physical exercise, to meet the social demand for high skilled sports talents.

System of human culture must learn educational content. The top priority of college physical education work is to manage college physical education work well. In the university, we desalinate, ignore, or even reject it, which eventually leads us to gradually give up physical education. Most of the students majoring in physical education enter the university by taking part in the unified physical education examination and the college entrance examination mode of cultural courses. Before entering the university, there is little learning time for college physical training. This directly leads to the poor performance of most students in physical education and better performance in cultural classes. Looking at the existing literature on physical education in colleges and universities, elective courses for physical education are uneven. A large number of students only stay on the surface of their knowledge and lack practical ability in learning sports skills. Few students truly master physical training in colleges.

$\mathrm{Li}$ et al. believe that broadband connection and mobile technology are widely used in the world. With the development 
of these advanced technologies, the application of intelligent devices and the access to the mobile Internet have made a huge leap, leading to the increasing scale and complexity of mobile network, which poses an urgent challenge to the anomaly detection of mobile network. The authors discuss the challenges and current literature of anomaly detection in cellular networks to meet the "big data" era. First of all, they reviewed the latest technology in the field of anomaly detection in cellular networks and finally introduced a method of anomaly detection in cellular networks based on big data analysis, but the lack of specific data [1]. Ahmad et al. believe that the growing gap between users and big data analysis requires innovative tools to cope with the challenges of big data volume, diversity, and speed. The progress of big data application and data science also brings new challenges. High performance computing solution has become a key problem. It needs a system that can effectively analyze the big data flow in its requirements. The algorithm can effectively deal with a large number of datasets. The system is implemented in the top tool of Hadoop parallel node and generates and processes graphics in near real time. By considering the system throughput and processing time, the system has better scalability and efficiency, but the development of tourism resources is still fuzzy [2]. Bognar thinks that a system can collect and analyze different types of financial data to support traders' decision-making. It makes use of large data platform Oracle and extends Oracle database with Oracle $\mathrm{R}$, which makes it possible to execute $r$ script embedded in database server, speeds up data processing, and combines the process of extraction, conversion, and upload with sentiment analysis module based on dictionary, which is realized through correlation analysis and Granger causality test, but there is no specific direction at present [3].

The innovation of this paper lies in the use of literature method, experimental investigation method, and the use of big data spectral clustering algorithm experiment, in order to study the method system of college students' physical training, through the tracking comparison and analysis of college physical training methods, based on the application of big data embedded system in college sports physical training $[4,5]$.

\section{Big Data Embedded System Method}

2.1. Connotation of Big Data. Erudition is a new word that has just appeared in recent years. It is the product of the Internet society. At present, people's views on it have not yet come up. They can only roughly know that it is related to the Internet $[6,7]$. We believe that big data refers to technical resources and information services that can be used to assist decision-making. Considering the huge amount of data, the diversity of analysis, and processing standards, quarrying is a common method and it's the best way [8-10].

2.2. Characteristics of Big Data. Big data contains a lot of data and different types of data [11, 12]. The software should be used to complete the processing of relevant datasets within the specified period, analyze the basis of the decision-making process, and consider the value of a large amount of information. Big data has the following characteristics.

2.2.1. The Amount of Data Is Huge and Complex. The amount of data is huge, the general standard database does not have the ability to collect and store, and the data type is rich. The data source is complex, has different structures and media formats, and is far from what a general database can manage and analyze. This requires an efficient database to process and analyze it, tap the potential value of the data, and reflect its important role in promoting economic development $[13,14]$.

2.2.2. The Processing Speed Is Very Fast. Big data has higher and higher requirements for information technology, and the changes of data are not the same, so timely data processing is particularly important $[3,15]$. In addition to data collection, it is also necessary to analyze and extract data, as well as the preferences and behaviors of data subjects, so that we can respond to reference requirements in real time [16-18].

\subsubsection{Using Data Analysis to Obtain Valuable Information.} The core of big data is not the preservation and simple processing of big data, but the specific analysis of these data and then getting important information $[16,19]$.

\subsection{Research Method}

2.3.1. Literature Method. According to the requirements of this study, CNKI in China has Doctoral Dissertation FullText Database. Chinese academic journals have published monographs such as databases and libraries on the Internet, focusing on the understanding of college physical education [20]. Curriculum, teaching methods of physical training in colleges and universities of education major, provides a theoretical basis for the research of this topic.

2.3.2. Experimental Investigation Method. A questionnaire survey was conducted among the technical teachers and students of physical education major in colleges and universities. The questionnaire was designed for the leaders or coaches of colleges and universities who are in charge of or take charge of after-school training, as well as the students participating in the training, so as to investigate and understand the current situation of after-school physical training in colleges and universities.

2.3.3. Logical Method. In the process of writing this paper, the logical analysis method is used to understand the problems, clarify the framework of this paper, and then sort out, analyze, compare, and summarize the survey data, so as to understand and determine the content plan of this paper through various channels and aspects. 


\section{Big Data Algorithm Related Experiments}

3.1. Big Data Spectral Clustering Algorithm. Laplacian figure is the main spectral tool matrix, and the field of studying these matrices is called spectral theory. The experiment explains the Laplacian matrix of different graphs and its main properties. According to different Laplacian variables, they are different here. There is no unique method to determine which matrix is a graph of Laplacian matrix in the literature. The author calls this matrix a graph of Laplacian matrix in his paper. Therefore, the reference energy of Laplacian matrix is different under different literacy rates. Suppose $f$ is a weighted undirected graph and its weight matrix is $h$. The definition of Laplacian matrix of nonstandard graph is as follows:

$$
F=H-W .
$$

The most important aspect of Laplacian matrix used in spectral clustering is that the vector formula on any real number field is as follows:

$$
F=\frac{1}{2} \sum_{i, j=1}^{n} h_{i j}\left(f_{i}-f_{j}\right)
$$

In the literature, there are two matrices called Laplacian matrices of standardized graphs, which are closely defined by the following formula:

$$
F_{\text {sym }}=R^{-1} L=I-D^{-1} W .
$$

3.2. Parallel Spectral Clustering Algorithm for Big Data. Given the spectral clustering algorithm of $n$ points, a similarity matrix $A \in R$ is constructed. The elements in the matrix are equal to or greater than $b_{i j} \geq 0$. The common spectral clustering algorithm standard spectral clustering is considered, and then the similarity information is used to divide these points into $k$ classes. The most common similarity function is Gaussian function:

$$
F_{i j}=\exp \left(\frac{\left|b_{i}-b_{j}\right|^{2}}{2 \sigma^{2}}\right) .
$$

Once the similarity matrix is formed, the spectral algorithm can be used to calculate the Laplacian matrix. Since there are several forms of Laplacian matrix, the standard symmetric Laplacian matrix formula is considered as follows:

$$
F_{\text {sym }}=I-D^{-(1 / 2)} \mathrm{BD}^{-(1 / 2)},
$$

where $D$ is a diagonal matrix, and

$$
d_{i j}=\sum_{j=1}^{n} b_{i j}
$$

Spectral clustering algorithm should calculate the first $n$ eigenvectors of Laplacian matrix, corresponding to the first $n$ minimum eigenvectors. Laplacian matrix is usually rare in this graph. The decomposition of the spacing radius of graphite Laplacian matrix represents the initial graph data points of the cluster in low dimensional space. Thus, the feature degradation part is the main stage of spectral calendar algorithm. It is assumed that the first $n$ eigenvectors formed are a moment array $f_{i j}$; then, the algorithm obtains the matrix $R$ by normalizing the row vectors of matrix $F$ :

$$
r_{i j}=\frac{f_{i j}}{\left(\sum_{n=1}^{j} f \text { in }^{2}\right)} .
$$

3.3. Embedded System. Embedded system usually refers to a device or device that has computer functions but is not called a computer. They are not general systems, but the specific computer system with strict requirements for application software and hardware can be reduced. The function, reliability, cost, and volume can be reduced, and the comprehensive requirements for power consumption can be reduced. In short, the embedded system is a set of application software and hardware in one system, with small software code, high degree of automation, fast response, and other characteristics. In particular, an embedded system which needs real-time and multitask is mainly composed of embedded processor, related support equipment, embedded operating system, and application software system. This system has been widely used in mobile and handheld computers.

\section{Application of Data Embedded System in College Physical Training}

4.1. Function Analysis. In the high-level directional physical training in colleges and universities, most coaches think that endurance, speed, and strength training should be given priority to, while giving consideration to physical training, flexibility, and sensitivity. Speed endurance is the life of long-distance sports, and in the competition, it needs the mutual conversion of nondirectional fast running, such as nonstop acceleration running, variable speed running, and fast start, which shows that the cultivation of speed endurance of physical training is an important content of physical training; this requires that the carrier can train middle school students to have good body sensitivity and flexibility of joint ligaments. Due to the irregularity of the competition field, physical training often needs to overcome the terrain obstacles with leaping, jumping, and other actions in the competition, which requires physical training students to have good fast strength, explosive power, acceleration ability, and body coordination ability. The high or low of these comprehensive abilities determines the students' competitive level. The training content is shown in Table 1.

Students' physical quality refers to their basic sports ability to participate in competitions. They are not one of the functions of the central nervous system because they are controlled by various motor skills. Through the function of these muscles, the human body can respond to the function 
through various organs and systems, such as rapid movement, continuous and rapid activities, and rapid functional ability and antiload ability. These sports abilities show the strength of students' physical training muscle strength, body sensitivity, joint ligament flexibility, and cardiopulmonary endurance. Research on the content and importance of student's physical training is shown in Figure 1.

Because the students need to complete the competition at the fastest speed in the shortest time, the students' physical training must choose the most economical and effective way to complete the competition. The ability of quick map recognition is the performance of the ability of quick response of the central nervous system in the physical training of the students. Because the orientation needs to be stopped at any time in the competition, repeated map recognition and positioning are to test whether the central nervous system of physical training can adapt to the intensity of the competition and make correct judgment timely.

\subsection{Physical Training Block Diagram of Embedded System.} The hardware design of big data embedded system is the second-generation microprocessor of Motorola Longzhu series, which provides abundant interface resources. The design block diagram of the whole machine is shown in Figure 1. The system is the core. During the peripheral period, there are mainly memory interfaces. It can not only store program code, but also dynamically store data. The function of interface can not only be used as the interface for communication with the machine, but also can be switched to infrared interface to communicate with external infrared interface. In order to provide friendly human-computer interface, the interface design of keyboard input and display is also as shown in Figure 2.

\subsection{Physical Training of Physical Education in Colleges and} Universities. In the consolidation stage of physical training in colleges and universities, teachers should actively change the practice methods and some characteristics of technical movements. In the automation stage of physical education teaching in colleges and universities, we should focus on circular practice and competition. The number of practices is increasing, so that students' physical quality can be improved gradually, so as to improve the students' skill level. At the same time, more competitions will be held to make students constantly understand the various situations that may be encountered in the competition and enhance the students' ability to respond and overcome difficulties in complex environment. Teachers should pay attention to the differences of students' level and systematically and comprehensively teach the students with weak foundation. On this basis, for students with certain motor skills, the improvement of their attention skills and their proficient use of skills are shown in Table 2 .

After all, the most important time to improve the physical training in colleges and universities is from the exercise table. $40.6 \%$ of the students spend more time on physical exercise and $10.7 \%$ of the students spend more time on extracurricular activities, indicating that half of the
TABle 1: Contents of students' physical training.

\begin{tabular}{lc}
\hline Serial number & Training content \\
\hline 1 & Speed \\
2 & Endurance \\
3 & Strength \\
4 & Flexibility \\
5 & Sensitive \\
6 & Mentality \\
\hline
\end{tabular}

students will continue to exercise after class, which is conducive to the mastery of sports skills. However, half of the students spend very less time on physical training skills in colleges and universities, and classroom time is limited. If the physical training in colleges and universities is not to consolidate sports skills, it is difficult to master sports skills as shown in Figure 3.

Colleges and universities should pay attention to the cultivation of students' theoretical knowledge of motor skills and actively promote the opening of motor skills learning and control theory courses. Elective courses should take into account the sports that can be connected with primary and secondary school courses. In the form of classroom organization, it is conducive to the consolidation of students' basic skills and improved the quality of educational practice. We should strengthen the development of physical education teachers' ability, constantly update teaching concepts, and attach importance to the introduction of young teachers. The selection of teaching methods of motor skills can comprehensively consider the various stages of the formation of motor skills, teaching content, and students' characteristics, and teaching methods should be selected according to the specific classroom needs. At the same time, in the process of teaching, from the perspective of motor skill transfer, we should adopt the teaching method from simple to complex and from easy to difficult and make rational use of the positive transfer between skills.

4.4. Investigation on Information Data System of Physical Fitness Training in Colleges and Universities. Now, we have entered the information age. Information technology has gradually integrated into all aspects of society and has a huge impact on human production and life. In the field of management, the information that can support and promote human social activities and can affect human production and business activities is generally called management information. The information is composed of batch data through integration, classification, and other processing. The university sports health information system is composed of multiple elements that support and influence each other. It is an organic whole that can realize special functions. The whole itself is also an element of the upper system. Different components of the system establish a relatively fixed order and structure. The management system is a unified whole for comprehensive management of different components. The system model is shown in Figure 4.

From the information system, we can see that the training time of college students in school is only years. 


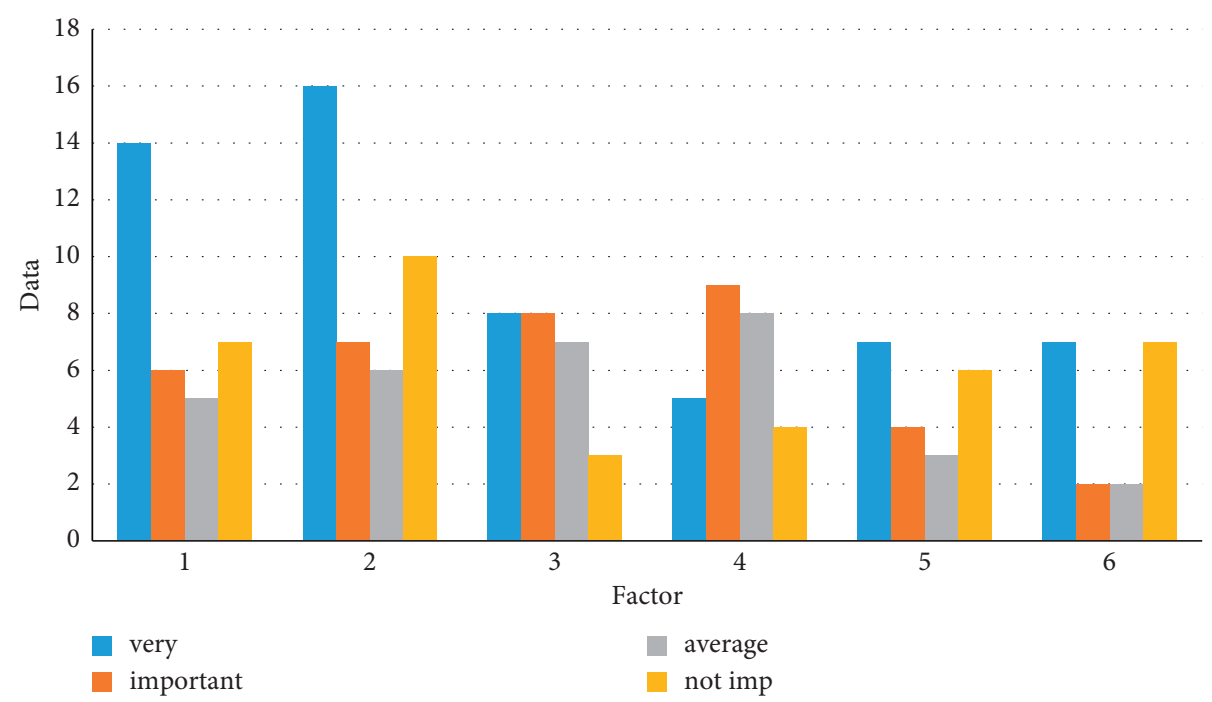

FIGURE 1: Research on the content and importance of students' physical training.

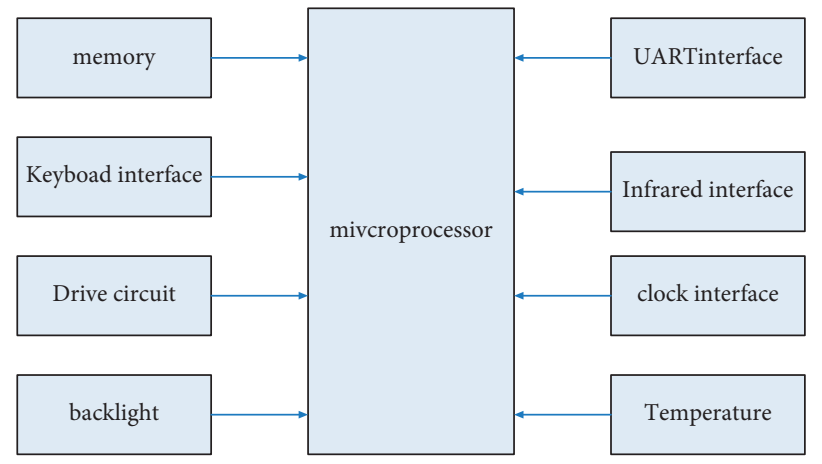

FIGURE 2: Block diagram of embedded system design.

TABLE 2: Sports years of physical education students before entering school.

\begin{tabular}{lcc}
\hline Time & Number of people & Percentage \\
\hline Three months & 25 & 25.6 \\
Half a year & 16 & 20.4 \\
One year & 33 & 35.5 \\
Two years & 23 & 20.5 \\
More than two years & 45 & 45 \\
\hline
\end{tabular}

During this period, students should not only learn various subjects, but also participate in heavy daily training. This requires college students to participate in training, while learning each course well, and deal with the relationship between learning and training. Of course, learning each basic theory and technical course well can also promote their training. The time of students' physical training is shown in Table 3.

It can be seen that college students have little training in their daily training. At ordinary times, colleges and universities have no high requirements for athletes' training. Management is not very strict. Absence and insufficient training intensity are inevitable in the system. The daily physical training arrangement is shown in Table 4.

At the same time, in the training process, traditional Chinese medicine is used in the training method. In order to meet the requirements of human muscle characteristics, two or more training movements are combined, which is helpful for college students in physical training. Continuous and uninterrupted training can effectively solve the one sidedness and incompleteness of single training method and make the training more effective, with methods to achieve threedimensional and comprehensive training effect. Its most outstanding advantage is that the majority of teachers and coaches, according to their past training and years of practical teaching experience, design reasonable and sound training. The training method is no longer the same for different students; they have more flexibility and autonomy. On the other hand, due to the diversity of training methods and contents, every training team has its own advantages. The results show that the training duration is short, which can avoid students' fatigue and boredom and significantly improve the training effect. Students' preferences and choices of sports are shown in Figure 5. 


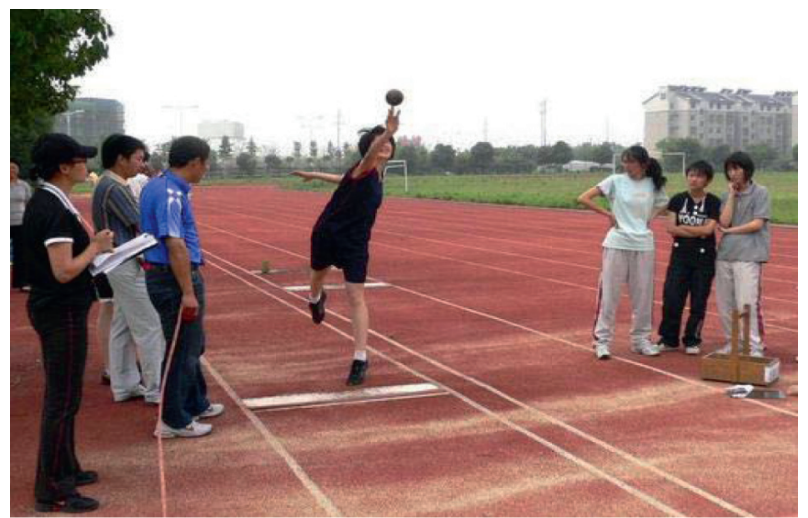

FIGURe 3: Physical training of college sports (http://alturl.com/g6dyv).

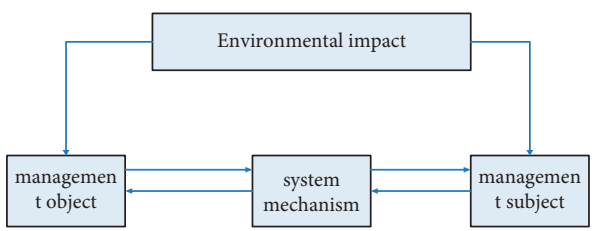

Figure 4: Information system structure.

TABle 3: College physical training time.

\begin{tabular}{lcc}
\hline Weekly physical training time & Frequency & Proportion (\%) \\
\hline 0.5 & 6 & 35 \\
1 & 6 & 30 \\
2 & 5 & 25 \\
4 & 2 & 10 \\
6 & 1 & 5 \\
\hline
\end{tabular}

College sports information management system relies on high-tech means to achieve data collection, input, memory and management, transmission, etc., in order to improve the management efficiency, but also can help managers to provide decision-making basis and grasp the management process. Because each field has its own particularity, the applicable management system of each industry is different after information penetration. Only according to the needs of the industry, the design of the management information system can achieve the specific analysis of the specific industry, and the systematic management can be realized. It has a good effect. In the field of competitive sports, training is the core and basic activity because the sports field is closely related to education. It is also industry related, but competitive, because its particularity can not be ignored. To realize information management in this field, we cannot copy the successful works of other industries. Compared with foreign countries, the domestic implementation of information management in the field of sports is not perfect. On the basis of studying the successful models in the world, we should combine China's national conditions with the needs of sports training. The management information system with strong pertinence is developed and put into practice for continuous optimization. It must be noted that,
TABle 4: Physical training arrangement in colleges and universities.

\begin{tabular}{lcc}
\hline Training content & Schedule & Load \\
\hline Jumping & Thursday & 15 \\
200 meters & Wednesday & 20 \\
Technical action & Monday, Friday & 10 \\
1000 meters & Monday & 35 \\
Throwing & Thursday, Saturday & 10 \\
Vulnerable projects & Sunday afternoon & 20 \\
\hline
\end{tabular}
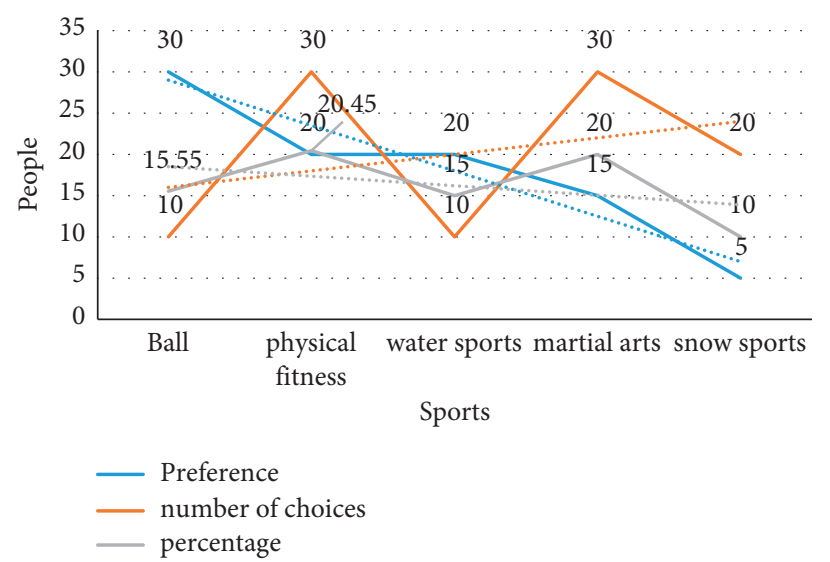

Figure 5: Favorite sports training items of college students.

TABLE 5: Information system page.

\begin{tabular}{lc}
\hline Serial number & Page \\
\hline 1 & User information management \\
2 & Training plan management \\
3 & Training effect evaluation \\
4 & Competition information management \\
5 & Scientific research information management \\
\hline
\end{tabular}

no matter how to adapt to the special needs of different industries, information management system must have an indispensable function regarding data collection, input, memory and transfer, maintenance, and management. The system page is shown in Table 5 .

\section{Conclusions}

This paper uses the literature method, experimental investigation method, and big data spectral clustering algorithmrelated experiments to study the advantages of big data and uses the value of big data and embedded system model to study the university sports physical fitness training information system based on big data mobile terminal. Physical training refers to the use of reasonable training methods to make athletes adapt to the level of training activities in body shape, technology, and sports ability. In the training, the continuous training method, intermittent training method, and combination training method should be used reasonably according to different people and different regions. At the same time, we should learn and sum up the successful 
experience at home and abroad, formulate advanced and scientific training programs, rationally allocate the student team, scientifically and reasonably train students, and strengthen the psychological quality training and training monitoring of college students. The physical function of athletes should be checked and analyzed regularly to ensure the quality of competition. Sweet good condition can give full play to the potential of college students and improve their quality level and technical level. The system can improve the speed and editing degree of data collection and statistics of senior high school students with sports specialty. The dynamic implementation of the classification of data transmission has played a good integration effect and realized the rapid development of training information. Modern information technology is applied in the training management of high school sports students to assist principals and teachers in charge, using information technology to optimize the existing management of specialty students. Through the combination of information technology, education, and sports talent training, we will continue to improve the quality and efficiency of the corresponding management.

\section{Data Availability}

No data were used to support this study.

\section{Conflicts of Interest}

The author declares that there are no conflicts of interest with any financial organizations regarding the material reported in this manuscript.

\section{Acknowledgments}

This work was supported by Yinchuan Energy College's 2020 school-level undergraduate teaching project "University Sports-Volleyball" curriculum teaching reform project (2020-JG-X-24). Ningxia Hui Autonomous Region's 2020 first-class undergraduate course "University Sports-Volleyball" funded the project.

\section{References}

[1] B. Li, S. Zhao, R. Zhang, Q. Shi, and K. Yang, "Anomaly detection for cellular networks using big data analytics," IET Communications, vol. 13, no. 20, pp. 3351-3359, 2019.

[2] A. Ahmad, A. Paul, S. Din, M. M. Rathore, G. S. Choi, and G. Jeon, "Multilevel data processing using parallel algorithms for analyzing big data in high-performance computing," International Journal of Parallel Programming, vol. 46, no. 3, pp. 508-527, 2018.

[3] E. Bognar, "Applying big data technologies in the financial sector-using sentiment analysis to identify correlations in the stock market," Computational Methods and Function Theory, vol. 4, no. 1, pp. 5-12, 2016.

[4] M. M. Rathore, H. Son, A. Ahmad, A. Paul, and G. Jeon, "Real-time big data stream processing using GPU with spark over hadoop ecosystem," International Journal of Parallel Programming, vol. 46, no. 3, pp. 630-646, 2018.
[5] E. Ngai, F. Dressler, V. Leung, and M. Li, "Guest editorial special section on internet-of-things for smart cities and urban informatics," IEEE Transactions on Industrial Informatics, vol. 13, no. 2, pp. 748-750, 2017.

[6] R. Rodrigo, H. Bruno, D. Vinícius, V. V. dos Santos Dias, R. Ferreira, W. Meira Jr. et al., "Watershed-ng:an extensible distributed stream processing framework," Concurrency and Computation: Practice and Experience, vol. 28, no. 8, pp. 2487-2502, 2016.

[7] K. Kanoun, C. Tekin, D. Atienza, and M. van der Schaar, "Bigdata streaming applications scheduling based on staged multiarmed bandits," IEEE Transactions on Computers, vol. 65, no. 12, pp. 3591-3605, 2016.

[8] J. Wan, D. Zhang, A. V. Vasilakos, and J. Lloret, "Guest editorial: special issue on cloud-integrated cyber-physical systems," IEEE Systems Journal, vol. 11, no. 1, pp. 84-87, 2017.

[9] W. Yan, C. Yan, Z. Ding et al., "A multilevel index model to expedite web service discovery and composition in large-scale service repositories," IEEE Transactions on Services Computing, vol. 9, no. 3, pp. 330-342, 2016.

[10] R. Ayachi, M. Afif, Y. Said, and M. Atri, "Traffic signs detection for real-world application of an advanced driving assisting system using deep learning," Neural Processing Letters, vol. 51, no. 1, pp. 837-851, 2020.

[11] H. C. Wang and Z. Dong, "Big data services drive mobile crowd embedded opportunistic control mechanism for biological engineering," EURASIP Journal on Embedded Systems, vol. 2016, no. 13, pp. 1-8, 2016.

[12] H.-M. Chen, R. Kazman, and S. Haziyev, "Strategic prototyping for developing big data systems," IEEE Software, vol. 33, no. 2, pp. 36-43, 2016.

[13] M. Ali and L. T. Jung, A.-H. Abdel-Aty, M. Y. Abubakar, M. Elhoseny, and I. Ali, Semantic-k-NN algorithm: an enhanced version of traditional k-NN algorithm," Expert Systems with Applications, vol. 151, Article ID 113374, 2020.

[14] J. Vellingiri, S. Balambigai, K. Saravanan, and R. Asokan, "Secure real time web based electrocardiogram monitoring system for improved healthcare," Journal of Medical Imaging and Health Informatics, vol. 6, no. 3, pp. 774-778, 2016.

[15] B. Xiong, L. Yang, S. Zheng, P. Cao, W. Xiaohua, and G. Wu, "Design and test of precise blanking control system for lactating sows," Transactions of the Chinese Society of Agricultural Engineering, vol. 33, no. 20, pp. 177-182, 2017.

[16] Z. H. Hu, J. X. Zhou, M. J. Zhang, and Y. Zhao, "Methods for ranking college sports coaches based on data envelopment analysis and PageRank," Expert Systems, vol. 32, no. 6, pp. 652-673, 2016.

[17] D. Jing and Q. Yan, "Design of college sports culture communication platform under the silk road," Automation and Instrumentation, no. 5, pp. 103-104, 2016.

[18] L. Fabisiak, "Web service usability analysis based on user preferences," Journal of Organizational and End User Computing, vol. 30, no. 4, pp. 1-13, 2018.

[19] C. Giannattasio, M. Failla, A. Grappiolo et al., "Effects of physical training of the dominant arm on ipsilateral radial artery distensibility and structure," Journal of Hypertension, vol. 19, no. 1, pp. 71-77, 2016.

[20] S. Bertram, K. Brixius, and C. Brinkmann, "Exercise for the diabetic brain: how physical training may help prevent dementia and alzheimer's disease in T2DM patients," Endocrine, vol. 53, no. 2, pp. 350-363, 2016. 